\title{
OPTIMASI JALUR DISTRIBUSI PADA KOPKAR PT. YKK AP INDONESIA DENGAN METODE SAVING MATRIX \\ ${ }^{1}$ Rizki Ayuning Tyas, ${ }^{2}$ Syahrizal Dzulqarnain, ${ }^{3}$ Qurrotul Aini
}

${ }^{1,2,3}$ Sistem Informasi, Fakultas Sains dan Teknologi, Universitas Islam Negeri Syarif Hidayatullah Jakarta, Jl. Ir H. Juanda No.95, Cemp. Putih, Kec. Ciputat, Kota Tangerang Selatan, 15412

Email: rizki.ayuning17@mhs.uinjkt.ac.id, syahrizal.dzulqarnain17@mhs.uinjkt.ac.id, qurrotulaini@uinjkt.ac.id

(Diterima:21 Desember 2019,direvisi:5 Mei 2020, disetujui:12 Mei 2020 )

\begin{abstract}
KOPKAR PT. YKK AP INDONESIA is one of the cooperative bodies in the Regency of Tangerang which has a rental unit, this rental unit cooperates with PT. YKK AP INDONESIA to distribute the products. However, their distribution routes are still ineffective, random, and carelessly to the detail of the distances. It affected the high-costs distribution process. A method of saving matrix used in this research to determine the distribution route to the destination market in a way that distribution route must be passed, the number of vehicles, its capacity to get shorter routes, and low-cost transportation. From the data processing and discussion, we concluded that saving matrix can reduce company expenses from 1.082,8 $\mathrm{km}$ to $912,9 \mathrm{~km}$, it also saved the distribution costs by Rp. 71.151/day or Rp. 2.134.530/month.
\end{abstract}

Keywords: Distribution, Transportation, Saving Matrix

\begin{abstract}
ABSTRAK
KOPKAR PT. YKK AP INDONESIA adalah salah satu lembaga koperasi yang ada di Kabupaten Tangerang yang memiliki unit sewa menyewa, yang dimana unit sewa menyewa bekerja sama dengan PT.YKK AP INDONESIA untuk mendistribusikan produknya. Jalur distribusi yang dilakukan oleh koperasi ini masih belum efektif dan acak, tidak memperhatikan lokasi dan jarak yang dituju, yang mengakibatkan timbulnya biaya yang besar untuk alur distribusi ini. Dalam penelitian ini metode yang akan digunakan adalah saving matrix. Metode saving matrix adalah metode yang digunakan untuk menentukan rute distribusi produk ke wilayah pemasaran dengan cara menentukan rute distribusi yang harus dilalui dan jumlah kendaraan berdasarkan kapasitas dari kendaraan tersebut agar diperoleh rute terpendek dan biaya transportasi yang minimal. Dari pengolahan data dan pembahasan diperoleh hasil bahwa metode saving matrix mampu meminimalkan total jarak tempuh untuk distribusi produk dari $1.082,8 \mathrm{~km}$ menjadi $921,9 \mathrm{~km}$. Penggunaan metode saving matrix juga dapat menghemat pengeluaran perusahaan sebesar Rp 71.151 /hari atau Rp 2.134.530/bulan dalam menjalankan distribusi produknya.
\end{abstract}

Kata Kunci: Distribusi, Transportasi, Saving Matrix

\section{PENDAHULUAN}

KOPKAR PT. YKK AP INDONESIA adalah salah satu lembaga koperasi yang ada di kabupaten Tangerang. Koperasi ini didirikan pada tanggal 12 Oktober 1996 yang berkedudukan di Jalan Manis Raya No.23 Desa Kadu, Kecamatan Curug, Kabupaten Tangeran, Banten. Koperasi ini pada awalnya bernaungan terhadap perusahan PT.YKK AP INDONESIA yang merupakan salah satu anak perusahaan dibawah naungan YKK Group. Namun, seiring berjalannya waktu koperasi ini berdiri sendiri sejak adanya perubahan anggaran selama hampir 3 kali pada tahun 2007. Koperasi ini memiliki unit yang terdiri dari Unit Simpan Pinjam Pembiayaan Syariah (USPPS), Unit Perdagangan, Unit Sewa Menyewa, Unit Payment, dan lain-lainnya. Dari semua unit yang ada di koperasi ini, unit sewa menyewa menjadi unit yang sangat erat bekerja sama dengan PT.YKK AP INDONESIA.

Unit sewa menyewa ini memiliki beberapa truk yang disewakan kepada PT.YKK AP INDONESIA yang memiliki produk utama adalah produk aluminium ekstrusi finished goods yang berupa jendela, pintu, dan curtain wall, selain dari aluminium profil batangan storefront. Peran PT. YKK AP INDONESIA bukan hanya melalui produk-produknya yang dapat diaplikasikan mulai dari rumahrumah mewah maupun di gedung-gedung bertingkat, melainkan juga kontribusi teknologi dan modal 
untuk pengembangan produk aluminium arsitektural di Indonesia, selain meningkatkan penerimaan devisa negara yang ikut memenuhi kebutuhan dalam negeri maupun negara-negara lain, seperti: Jepang, Singapura, Taiwan, Thailand, Malaysia, Vietnam, Brazil, dan Amerika Serikat [1].

Distribusi adalah kegiatan penyaluran hasil produksi berupa barang dan jasa dari produsen ke konsumen guna memenuhi kebutuhan manusia. Distribusi merupakan kegiatan yang harus dilakukan oleh pengusaha untuk menyalurkan, mengirimkan, menyebarkan, serta menyampaikan barang yang dipasarkannya kepada konsumen [2]. Distribusi bertujuan agar benda-benda hasil produksi sampai kepada konsumen dengan lancar, tetapi harus memerhatikan kondisi produsen dan sarana yang tersedia dalam masyarakat, di mana sistem distribusi yang baik akan sangat mendukung kegiatan produksi dan konsumsi [3].

Saluran distribusi merupakan suatu jalur yang harus dilalui oleh arus barang dari produsen ke agen atau perantara atau pedagang besar terhadap pemakai, dalam hal ini konsumen [4]. Saluran distribusi diartikan sebagai jalur distribusi suatu barang atau jasa, yang berarti rute-rute yang akan dilalui barang atau jasa sehingga bisa sampai kepada konsumen. Penggunaan rute pengiriman yang efisien dan tepat akan menghasilkan barang atau jasa yang disalurkan sampai dalam kondisi yang baik disertai pengiriman waktu yang efisien dan biaya yang minim.

Pada penelitian ini, peneliti melakukan optimasi terhadap jalur distribusi yang sudah diterapkan oleh KOPKAR PT. YKK AP INDONESIA dalam membantu mendistribusikan produk dari perusahaan. Pengertian optimasi itu sendiri adalah pencapaian suatu tindakan atau keadaan terbaik dalam sebuah masalah keputusan dibawah pembatasan sumber daya yang tersedia. Tujuan dari penelitan ini adalah untuk menentukan jarak distribusi mana yang terbaik agar perusahaan memperoleh penghematan biaya operasionalnya. Agar dapat memperoleh jalur distribusi yang optimal maka peneliti menggunakan metode saving matrix.

Metode saving matrix adalah metode yang digunakan untuk menentukan rute distribusi produk ke wilayah pemasaran dengan cara menentukan rute distribusi yang harus dilalui dan jumlah kendaraan berdasarkan kapasitas dari kendaraan tersebut agar diperoleh rute terpendek dan biaya transportasi yang minimal. Metode saving matrix juga merupakan salah satu teknik yang digunakan untuk menjadwalkan sejumlah kendaraan terbatas dari fasilitas yang memiliki kapasitas maksimum yang berlainan [5].

Metode saving matrix merepresentasikan penghematan yang bisa direalisasikan jika sejumlah pelanggan digabungkan ke dalam satu rute. Untuk menentukan rute perjalanan, diperlukan informasi mengenai jumlah kebutuhan produk dari tiap lokasi distribusi. Saving matrix didapatkan dengan cara menggabungkan titik tujuan yang memiliki penghematan jarak yang terbesar dan memperhatikan volume permintaan tiap-tiap tujuan agar tidak melebihi kapasitas kendaraan [6].

Dalam penelitian ini cakupan permasalahannya adalah jalur distribusi yang diterapkan oleh KOPKAR PT. YKK AP INDONESIA. Jalur distribusi yang dilakukan oleh koperasi ini dalam membantu perusahaan ini masih belum efektif dan acak, tidak memperhatikan lokasi dan jarak yang dituju, yang mengakibatkan timbulnya biaya yang besar untuk alur distribusi ini. Batasan penelitian ini hanya dilakukan pada skala nasional, tidak mencakup skala internasional. Adapun hasil yang direncakan dari penelitian ini adalah didapatkannya optimasi jalur distribusi yang efektif dan efisien dari segi jarak, biaya dan waktu sehingga distribusi yang dilakukan oleh KOPKAR PT. YKK AP INDONESIA bisa seminimal dalam membantu perusahaan untuk bisa memuaskan para konsumen dalam menerima produk.

\section{TINJAUAN PUSTAKA}

Seperti yang dilakukan penelitian sebelumnya [7], yaitu pada penelitian yang dilakukan pada CV. Cap Mawar, terdapat hambatan dalam pendistribusian produk. Penelitian ini menggunakan metode saving matrix, yang dimana langkah awalnya adalah menentukan matrik untuk jaraknya. Berdasarkan hasil penelitian ini, diperoleh bahwa perusahaan melakukan penghematan biaya distribusi secara nilai efisiensi sebesar $34,1 \%$, yang dimana penghematan jarak distribusi sebesar $516 \mathrm{~km} / \mathrm{minggu}$ dan penghematan biaya distribusi sebesar Rp. 3.000.000/minggu.

Penelitian yang lainnya [8] juga menjelaskan bahwa metode saving matrix digunakan untuk menentukan rute distribusi produk dari wilayah pemasaran agar diperoleh rute terpendek dan biaya transportasi yang minimal. Penelitian ini dilakukan perusahaan Distribusi Minuman yang akan mendistribusikan produknya ke wilayah Kota Serang. Hasil dari penelitian ini diperoleh penghematan 
jarak menjadi 41,37 km dan penghematan dalam biaya distribusi diperoleh Rp. 93.312 /hari atau Rp. 2.799. 360 / bulan.

Penelitian [9] menyebutkan bahwa penelitian ini memuat masalah tentang bagaimana rute kendaraan untuk jalur distribusi di CV. Boang Shuttlecock. Penelitian ini menggunakan metode saving matrix yang dimana metode ini memberikan rute terpendek untuk meminimalkan biaya, jarak dan waktu yang dihabiskan perusahaan untuk distribusi. Sebelum pengoptimalan, perusahaan mengeluarkan biaya distribusi sebesar Rp. 5.882.771/bulan dan setelah dilakukan pengoptimalan ini maka pengeluaran biaya perusahaan ini menjadi Rp. 5.239.003/bulan. Penghematan biaya distribusi secara efisien sebesar $10,94 \%$ yang sangat menguntungkan untuk perusahaan itu sendiri.

Pada penelitian [10] juga dijelaskan bahwa penelitian ini memiliki masalah salah satunya adalah keterbatasan proses disribusi yang hanya satu kali pengiriman produk kepada satu warehouse saja sehingga menimbulkan jarak yang panjang dan biaya distribusi yang mahal. Oleh karena itu, dalam penelitian ini dilakukan pengoptimalan dengan menggunakan metode saving matrix yang berguna untuk menentukan rute distribusi berdasarkan rute terpendek dan biaya yang minimal. Dan hasil penelitian ini, setelah analisa dan dikelola datanya, maka didapat penghematan jarak atau rute sebesar $695,9 \mathrm{~km}$ atau sebesar 35,07\% dari rute atau jarak awal. Kemudian untuk penghematan biaya distribusi sebesar Rp. 4.497.345/bulan atau sebesar 43,53\% dari biaya distribusi yang dikeluarkan perusahaan diawal.

Pada penelitian [11] menjelaskan bahwa penentuan rute atau jalur distribusi sangat penting karena dapat menghemat biaya dan waktu yang diperlukan untuk suatu produk sampai kepada konsumen. Pada penelitian ini, tujuan dilakukannya optimasi jalur distribusi adalah untuk membuat jadwal pengiriman produk lebih efisien dan pemilihan rute yang memiliki penghematan waktu terbesar. Metode saving matrix menjadi metode yang dipilih oleh peneliti ini untuk melakukan optimasi terhadap kasus ini. Pada hasil penelitian ini, pengalokasian pengiriman dengan mempertimbangkan truk terkecil untuk digunakan terlebih dahulu jauh lebih menghemat waktu tempuh dibandingkan pengalokasian yang biasanya digunakan oleh perusahaan ini. Dengan menerapkan metode memprioritaskan kendaraan dengan kapasitas besar maka perusahaan memerlukan waktu tempuh yaitu 440,77 menit sedangkan dengan hasil dari metode usulan yang diberikan peneliti sebesar 369,67 menit. Dan pada metode usulan ini, jauh lebih meningkatkan efektivitas penggunaan armada yang tersedia dengan rata-rata penggunaannya sebesar $47 \%$.

Sesuai dengan penelitian [12] menjelaskan bahwa dilakukan penentuan rute transportasi pada PT. Lima Jaya Abadi dapat diselesaikan dengan metode saving matrix untuk menentukan rute distribusi produk ke wilayah pemasaran dengan cara menetukan rute distribusi yang harus dilalui dan jumlah kendaraan berdasarkan kapasitas dari kendaraan tersebut agar diperoleh rute terpendek dan biaya transportasi yang minimal. Dari hasil analisa dan pengelolahan data dengan penerapan metode saving matrix dari 13 rute awal menjadi 8 rute baru, dan didapat perbandingan pada rute awal sebesar 1984,3 $\mathrm{km}$ dan untuk rute baru sebesar 1288,4 km sehingga diperoleh penghematan jarak sebesar 695,9 km atau sebesar $35,07 \%$. Biaya total transportasi sebelum penerapan metode saving matrix yaitu di dapat pada rute awal sebesar Rp 10.331.825 /bulan, dan biaya total sesudah penerapan metode saving matrix pada rute A sampai rute $\mathrm{H}$ sebesar Rp 5.834.480 /bulan. Sehingga diperoleh penghematan biaya distribusi sebesar Rp 4.497.345 /bulan atau penghematan sebesar 43,53\%.

Penelitian lainnya [13] menjelaskan bahwa pendistribusian produk kemasan yang tidak melihat kapasitas armada membuat pengiriman hanya dilakukan kepada satu customer dalam sekali kirim yang membuat rute dan jarak semakin panjang, menjadi permasalahan yang harus dihadapi oleh PT XYZ. Hal ini menyebabkan pemborosan biaya distribusi yang harus dikeluarkan oleh perusahaan. Penelitian ini bertujuan untuk meminimumkan biaya dan usulan rute baru. Sampel dalam penelitian ini adalah data pengiriman pada 20 customer, jarak, biaya pengiriman dan produk yang dikirim ke wilayah Jabodetabek, Banten, Jawa Barat dan Jawa Tengah. Hasil pengolahan data pengiriman produk yang dilakukan oleh PT XYZ dengan jarak awal $2159 \mathrm{~km}$ dan setelah dilakukan pengurutan rute menggunakan metode nearest neighbor diperoleh jarak usulan $2000 \mathrm{~km}$ sehingga diperoleh selisih jarak $159 \mathrm{~km}$. Biaya pendistribusian awal sebesar Rp 15,240,473/bulan, setelah menggunakan metode saving matrix biaya usulan yang diperoleh sebesar 13,162,160/bulan dengan selisih biaya sebesar Rp 2,078,313/bulan. Sehingga biaya distribusi dan rute yang diusulkan menggunakan metode saving matrix dan nearest neighbor lebih optimum daripada rute awal.

Pada penelitian [5] rute transportasi merupakan satu solusi dalam meminimalkan biaya distribusi. 
Metode saving matrix merupakan satu metode dalam Vehicle Routing Problem (VRP) untuk mendapatkan rute yang efisien. Penggunaan metode ini dengan menggabungkan titik-titik tujuan yang memiliki penghematan jarak yang terbesar dan memperhatikan volume permintaan tiap-tiap tujuan. Lalu melakukan urutan kunjungan oleh kendaraan sehingga diperoleh rute pengiriman yang efisien. Dalam paper ini dibahas penerapan metode saving matrix dalam penentuan rute pengiriman produk pada perusahaan DEF. Dalam akhir pengerjaan, ditemukan bahwa metode ini menunjukkan rute yang didapat lebih sedikit dari rute awal yaitu dari enam rute menjadi lima rute. Dalam sebulan, diperoleh penghematan jarak sebesar $105 \mathrm{~km}$ atau sekitar $14 \%$, penghematan bahan bakar sebesar 21 liter atau sekitar 14\% sehingga penggunaan kendaraan menjadi berkurang yang berarti besarnya biaya dapat diminimumkan.

Dari beberapa penelitian sebelumnya yang telah disebutkan diatas, saving matrix terbukti efektif digunakan untuk mengoptimalkan rute distribusi atau transportasi agar lebih efisien antara jarak yang ditempuh dan biaya yang dikeluarkan. Sehingga pada penelitian kali ini, kami menerapkannya untuk optimasi jalur distribusi pada KOPKAR PT. YKK AP INDONESIA dalam meminimalkan total jarak tempuh dan menghemat pengeluaran perusahaan dalam menjalankan distribusi produknya.

\section{METODE PENELITIAN}

Selama penelitian, penelitian ini menggunakan beberapa metode untuk mengerjakan penelitian ini. Metode diterapkan selama penelitian ini dibagi menjadi 2, yaitu metode untuk pengumpulan data dan metode untuk pengelolaan data.

\subsection{Pengumpulan Data}

Data yang digunakan dalam penelitian ini terdiri atas:

1. Data Primer

Data primer yang diambil merupakan data yang diambil dari hasil observasi langsung ke KOPKAR PT.YKK AP INDONESIA dan wawancara dengan pihak Manajemen KOPKAR PT.YKK AP INDONESIA, yaitu Bapak Taufik selaku Ketua Manajemen PT.YKK AP INDONESIA. Berdasarkan hasil wawancara dan observasi, maka data yang didapatkan berupa data-data yang terkait dengan permasalahan, seperti data histori permintaan konsumen, data rute kendaraan, jumlah dan jenis kendaraan, serta rute pengiriman yang sudah ada. Kemudian data yang dibutuhkan lagi yaitu biaya perjalanan dan biaya tenaga kerja perusahaan ini.

2. Data Sekunder

Data sekunder yang kami dapat diperoleh berdasarkan hasil pencarian untuk referensi penelitian ini dari berbagai sumber seperti internet, buku, dan literatur lainnya yang berhubungan dengan penelitian ini.

\subsection{Pengelolaan Data}

Pada penelitian ini, untuk pengelolaan data menggunakan bantuan tools dari software microsoft excel yang dimana software ini membantu pengelolaan data dalam hal perhitungan. Pengelolaan data, yaitu dengan menghitung jarak yang harus dilalui kendaraan dari pabrik ke konsumen serta jarak antara konsumen ke konsumen, mengidentifikasi matriks penghematan dengan metode saving matrix, mengalokasi setiap konsumen ke kendaraan yang dimulai dari nilai penghematan terbesar dengan memperhatikan kapasitas dari kendaraannya, kemudian mengurutkan setiap permintaan dalam rute yang sudah ditentukan dengan menggunakan prosedur nearest neighbour, nearest insertion dan farthest insertion, lalu pilih rute yang akan digunakan berdasarkan jarak tempuh terpendek

Menurut [14] [15] langkah-langkah dalam metode saving matrix adalah sebagai berikut:

1. Menentukan Matriks Jarak

Pada penentuan matriks jarak ini, data jarak antara perusahaan dengan lokasi dan lokasi ke lokasi lainnya sangat diperlukan. Setelah mengetahui koordinat dari masing-masing lokasi, maka jarak antar kedua lokasi tersebut dapat dihitung dengan menggunakan rumus sebagai berikut:

$$
j_{(1,2)}={\sqrt{\left(x_{1}-x_{2}\right)+\left(y_{1}-y_{2}\right)}}^{2}
$$

Akan tetapi jika jarak antar kedua koordinat sudah diketahui, maka perhitungan menggunakan rumus tidak digunakan dan menggunakan jarak yang sudah ada.

2. Menentukan Matriks Penghematan (saving matrix) 
Setelah mengetahui jarak keseluruhan yaitu jarak antara pabrik dengan lokasi dan lokasi dengan lokasi lainnya, maka dalam langkah ini diasumsikan bahwa setiap lokasi akan dilewati oleh satu truk secara ekslusif. Artinya, akan ada beberapa rute yang berbeda yang akan dilewati untuk tujuan masing-masing. Dengan demikian akan ada penghematan apabila ada penggabungan rute yang dinilai satu arah dengan rute yang lainnya. Untuk mencari matriks penghematan dapat menggunakan rumus sebagai berikut;

$S_{(x, y)}=J_{(x, y)}+J_{(x, y)}-J_{(x, y)}$

$S_{(x, y)}$ merupakan penghematan jarak yaitu penggabungan antara rute $x$ dengan rute $y$.

3. Pengalokasian Kendaraan dan Rute Berdasarkan Lokasi

Setelah matriks penghematan diketahui, maka langkah selanjutnya adalah pengalokasian lokasi ke rute atau kendaraan. Artinya dalam langkah ini akan ditentukan rute pengiriman baru berdasarkan atas penggabungan rute pada langkah kedua di atas. Hasilnya adalah pengiriman lokasi 1 dan lokasi 2 akan dilakukan dengan menggunakan 1 rute.

4. Pengurutan Lokasi Tujuan dalam Suatu Rute

Langkah ini menentukan urutan kunjungan. Ada beberapa metode dalam menentukan urutan kunjungan, yaitu:

\section{a. Metode Nearest Insert}

Metode ini menentukan urutan kunjungan dengan mengutamakan lokasi yang kalau dimasukkan ke dalam rute yang sudah ada menghasilkan jarak yang minimum.

b. Metode Nearest Neighbour

Metode ini menentukan kunjungan dengan mengutamakan lokasi yang jaraknya paling dekat dengan lokasi yang dikunjungi terakhir.

c. Metode Farthest Insert

Metode ini menentukan kunjungan dengan memberikan perjalanan yang paling jauh.

\section{HASIL DAN PEMBAHASAN}

Berikut adalah uraian dari hasil pengumpulan data dan pengelolaan data yang telah dikerjakan, sebagai berikut:

\subsection{Pengumpulan Data}

Dari hasil observasi dan wawancara dengan pihak manajemen KOPKAR PT.YKK AP INDONESIA, berikut adalah uraian untuk masing-masing data yang dibutuhkan dalam penelitian ini.

a. Data Rata-Rata Permintaan Produk

Data rata-rata produk besarnya dalam bentuk batangan storefront untuk alumunium yang didistribukan pada periode Januari - Juni 2018 seperti pada Tabel 1.

Tabel 1 Data Rata-Rata Permintaan

\begin{tabular}{llll}
\hline Customer & Alamat & Jarak $(\mathbf{k m})$ & $\begin{array}{l}\text { Rata-Rata Permintaan } \\
\text { Produk }\end{array}$ \\
\hline I & Cengkareng, Jakarta & 27,2 & 140 \\
II & BSD City, Tangerang & 18,5 & 150 \\
III & MH. Tamrin, Cikarang Selatan & 82,1 & 120 \\
IV & Taneka Cikarang Hotel, Lippo - & 78,6 & 200 \\
V & Cikarang & 81,3 & 180 \\
VI & Kenari No.32, Cikarang & 24,7 & 230 \\
& BSD Savia, BSD City - & \\
VII & Tangerang & 35,4 & 175 \\
& Pergudangan Harapan Dadapan & \\
VIII & Jaya, Tangerang & 30,5 & 80 \\
IX & Grogrol Utara, Kebayoran- & 67,9 & 220
\end{tabular}

Tyas, Optimasi Jalur Distribusi Pada Kopkar PT. YKK AP Indonesia Dengan Metode Saving Matrix 


\begin{tabular}{|c|c|c|c|}
\hline$X$ & $\begin{array}{l}\text { Penjagalan Penjaringan, Jakarta } \\
\text { Utara }\end{array}$ & 35,7 & 315 \\
\hline XI & $\begin{array}{l}\text { Gedung Panin Life Center } \\
\text { Lantai 3A, Jakarta Barat }\end{array}$ & 30 & 300 \\
\hline XII & Puri Kembangan, Jakarta & 23 & 105 \\
\hline
\end{tabular}

b. Rute Awal Pendistribusian

Pada rute awal ini perusahaan mempunyai rute sebanyak 12 rute dan pendistribusian produk didistribusikan dalam satu kali pengiriman sebagai berikut dalam Tabel 2.

Tabel 2 Rute Awal Pendistribusian

\begin{tabular}{llc}
\hline Rute & $\begin{array}{l}\text { Rute Awal } \\
\text { Pengiriman }\end{array}$ & Jarak Tempuh $(\mathbf{k m})$ \\
\hline 1 & W - I - W & 54,4 \\
2 & W - II - W & 50 \\
3 & W - III - W & 164,2 \\
4 & W - IV - W & 157,2 \\
5 & W - V - W & 162,6 \\
6 & W - VI - W & 49,4 \\
7 & W - VII - W & 70,8 \\
8 & W - VIII - W & 61 \\
9 & W - IX - W & 135,8 \\
10 & W - X - W & 71,4 \\
11 & W - XI - W & 60 \\
12 & W - XII - W & 46 \\
\hline Total Jarak & $1.082,8$ \\
\hline
\end{tabular}

Data jarak antar satu distributor dengan distributor lainnya dapat dilihat pada Tabel 3.

Tabel 3 Jarak Antar Distributor $(\mathbf{k m})$

\begin{tabular}{lllllllllllll}
\hline & I & II & III & IV & V & VI & VII & VIII & IX & X & XI & XII \\
\hline PK & & & & & & & & & & & & \\
I & 0 & & & & & & & & & & & \\
II & 27,4 & 0 & & & & & & & & & & \\
III & 75,7 & 76,8 & 0 & & & & & & & & & \\
IV & 73,1 & 74,2 & 1,3 & 0 & & & & & & & & \\
V & 75,8 & 77,1 & 6,2 & 8,1 & 0 & & & & & & & \\
VI & 27 & 8,3 & 71,3 & 68,4 & 71,3 & 0 & & & & & & \\
VII & 10,9 & 31,1 & 68,4 & 66,8 & 69,7 & 35,2 & 0 & & & & & \\
VIII & 13,5 & 28,3 & 50 & 48,8 & 51,6 & 22,5 & 21,8 & 0 & & & & \\
IX & 35,6 & 59,9 & 37,3 & 36,6 & 39,5 & 54,1 & 36,7 & 33,9 & 0 & & & \\
X & 14,3 & 34,5 & 56,3 & 54,7 & 57,5 & 38,6 & 15,4 & 11,8 & 26,9 & 0 & & \\
XI & 21,8 & 28,5 & 49 & 48,8 & 51,6 & 32,7 & 22,9 & 5,9 & 32,9 & 7,2 & 0 & \\
XII & 4,3 & 22,7 & 74,8 & 57,6 & 60,5 & 28,5 & 13 & 9,8 & 38,3 & 17,1 & 13,7 & 0 \\
\hline
\end{tabular}

Data jarak dari pabrik hingga ke distributor dan antar distributor ke distributor diperlukan dalam menentukan nilai penghematan jarak yang dihasilkan berdasarkan metode saving matrix. Berikut adalah peta lokasi dari warehouse dan distributor dapat dilihat pada Gambar 1 sebagai berikut. 
c. Biaya Operasional

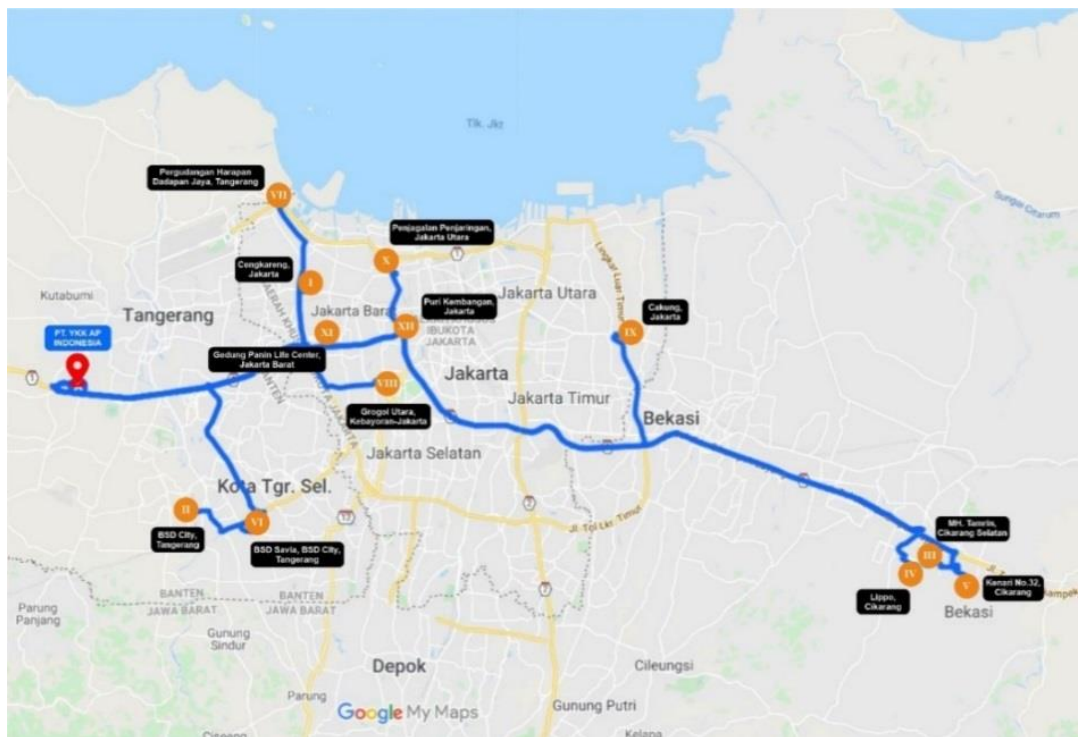

Gambar 1 Rute awal pendistribusian

Data biaya yang bersangkutan pada pendistribusian produk dari warehouse pusat sampai distributor-distributor, sebagai berikut pada Tabel 4.

Tabel 4 Rata-rata Biaya Operasional Pendistribusian (per Bulan)

\begin{tabular}{lc}
\hline Biaya Operasional & Jumlah $(\mathbf{R p )}$ \\
\hline Sopir, Kernet dan BBM & 8.326 .000 \\
Biaya Tol & 1.478 .500 \\
Biaya lainnya & 4.621 .222 \\
\hline Total & 14.425 .722 \\
\hline
\end{tabular}

\subsection{Pengolahan Data}

Berikut adalah uraian dari tahapan pengolahan data yang dibantu oleh software microsoft excel dalam hal perhitungan.

a. Menentukan Matrix Jarak

Metode saving matrix digunakan untuk meminimumkan jarak tempuh dengan membentuk subsub rute yang dalam hal ini adalah penggabungankan dua atau lebih titik penjemputan ke dalam satu rute. Langkah pertama yang dilakukan dalam metode saving matrix adalah mengidentifikasi matriks jarak yang terlihat pada Tabel 5 .

Tabel 5 Matriks Jarak Warehouse ke Distributor (km)

\begin{tabular}{llllllllllllll}
\hline & W & I & II & III & IV & V & VI & VII & VIII & IX & X & XI & XII \\
\hline W & 0 & & & & & & & & & & & & \\
I & 27,2 & 0 & & & & & & & & & & & \\
II & 25 & 27,4 & 0 & & & & & & & & & & \\
III & 82,1 & 75,7 & 76,8 & 0 & & & & & & & & & \\
IV & 78,6 & 73,1 & 74,2 & 1,3 & 0 & & & & & & & & \\
V & 81,3 & 75,8 & 77,1 & 6,2 & 8,1 & 0 & & & & & & & \\
VI & 24,7 & 27 & 8,3 & 71,3 & 68,4 & 71,3 & 0 & & & & & & \\
VII & 35,4 & 10,9 & 31,1 & 68,4 & 66,8 & 69,7 & 35,2 & 0 & & & & & \\
VIII & 30,5 & 13,5 & 28,3 & 50 & 48,8 & 51,6 & 22,5 & 21,8 & 0 & & & & \\
IX & 67,9 & 35,6 & 59,9 & 37,3 & 36,6 & 39,5 & 54,1 & 36,7 & 33,9 & 0 & & & \\
X & 35,7 & 14,3 & 34,5 & 56,3 & 54,7 & 57,5 & 38,6 & 15,4 & 11,8 & 26,9 & 0 & & \\
XI & 30 & 21,8 & 28,5 & 49 & 48,8 & 51,6 & 32,7 & 22,9 & 5,9 & 32,9 & 7,2 & 0 & \\
XII & 23 & 4,3 & 22,7 & 74,8 & 57,6 & 60,5 & 28,5 & 13 & 9,8 & 38,3 & 17,1 & 13,7 & 0 \\
\hline
\end{tabular}

b. Menentukan Matrix Penghematan

Langkah selanjutnya adalah melakukan identifikasi matrix penghematan dengan asumsi bawa Tyas, Optimasi Jalur Distribusi Pada Kopkar PT. YKK AP Indonesia Dengan Metode Saving Matrix 
setiap distributor akan dikunjungin oleh satu truk secara eksklusif. Dengan kata lain, akan ada 12 rute yang berbeda dengan satu tujuan masing-masing distributor. Contoh perhitungan jarak penghematan dari warehouse ke distributor 1 ke distributor 2 adalah sebagai berikut:

$S_{(x, y)}=J_{(w, y)}+J_{(w, y)}-J_{(x, y)}$

$S_{(x, y)}=27,2+25-27,4$

$S_{(x, y)}=24,8$

Jadi jarak penghematan dari distributor 1 ke distributor 2 sebesar 24,8 km. Dengan menggunakan rumus yang sama dihasilkan jarak penghematan sebagai berikut pada Tabel 6 .

Tabel 6 Hasil Perhitungan Jarak Penghematan (Savings)

\begin{tabular}{|c|c|c|c|c|c|c|c|c|c|c|c|c|}
\hline & I & II & III & IV & V & VI & VII & VIII & IX & $\mathbf{X}$ & XI & XII \\
\hline \multicolumn{13}{|l|}{$\mathrm{W}$} \\
\hline I & 0 & & & & & & & & & & & \\
\hline II & 24,8 & 0 & & & & & & & & & & \\
\hline III & 33,6 & 30,3 & 0 & & & & & & & & & \\
\hline IV & 32,7 & 29.4 & 159,4 & 0 & & & & & & & & \\
\hline V & 32,7 & 29,2 & 157,2 & 151,8 & 0 & & & & & & & \\
\hline VI & 24,9 & 41,4 & 35,5 & 34,9 & 34,7 & 0 & & & & & & \\
\hline VII & 51,7 & 29,3 & 49,1 & 47,2 & 47 & 24,9 & 0 & & & & & \\
\hline VIII & 44,2 & 27,2 & 0 & 60,3 & 60,2 & 32,7 & 44,1 & 0 & & & & \\
\hline IX & 59,5 & 33 & 112,7 & 109,9 & 109,7 & 53,1 & 66,6 & 64,5 & 0 & & & \\
\hline$X$ & 48,6 & 26,2 & 61,5 & 59,6 & 59,5 & 21,8 & 55,7 & 54,4 & 76,7 & 0 & & \\
\hline XI & 35,4 & 26,5 & 63,1 & 59,8 & 59,7 & 22 & 42,5 & 54,6 & 65 & 58,5 & 0 & \\
\hline XII & 45,9 & 25,3 & 30,3 & 44 & 43,8 & 19,2 & 45,4 & 43,7 & 52,6 & 41,6 & 393 & 0 \\
\hline Order & 250 & 150 & 120 & 200 & 180 & 230 & 175 & 320 & 220 & 315 & 300 & 215 \\
\hline
\end{tabular}

c. Mengalokasikan Hasil Distributor ke Rute Transportasi

Berdasarkan hasil perhitungan jarak penghematan, langkah selanjutnya adalah mengalokasikan distributor ke kendaraan atau rute. Dengan asumsi awal adalah 12 rute yang berbeda, akan tetapi dalam mengalokasikan distributor-distributor bisa digabungkan sampai batas kapasitas truk yang digunakan. Penggabungan akan dimulai dari nilai penghematan terbesar dengan tujuan memaksimumkan penghematan. Rute transportasi awal dapat dilihat pada Tabel 7, sebagai berikut:

Tabel 7 Rute Awal untuk Setiap Pendistribusian

\begin{tabular}{llllllllllllll}
\hline & W & I & II & III & IV & V & VI & VII & VIII & IX & X & XI & XII \\
\hline W & 0 & & & & & & & & & & & & \\
I & 27,2 & 0 & & & & & & & & & & \\
II & 25 & 24,8 & 0 & & & & & & & & & & \\
III & 82,1 & 33,6 & 30,3 & 0 & & & & & & & & \\
IV & 78,6 & 32,7 & 29,4 & 159,4 & 0 & & & & & & & \\
V & 81,3 & 32,7 & 29,2 & 157,2 & 151,8 & 0 & & & & & & \\
VI & 24,7 & 24,9 & 41,4 & 35,5 & 34,9 & 34,7 & 0 & & & & & \\
VII & 35,4 & 51,7 & 29,3 & 49,1 & 47,2 & 47 & 24,9 & 0 & & & & & \\
VIII & 30,5 & 44,2 & 27,2 & 0 & 60,3 & 60,2 & 32,7 & 44.1 & 0 & & & & \\
IX & 67,9 & 59,5 & 33 & 112.7 & 109,9 & 109,7 & 53,1 & 66,6 & 64,5 & 0 & & & \\
X & 35,7 & 48,6 & 26,2 & 61,5 & 59,6 & 59,5 & 21,8 & 55,7 & 54,4 & 76,7 & 0 & & \\
XI & 30 & 35,4 & 26,5 & 63,1 & 59,8 & 59,7 & 22 & 42,5 & 54,6 & 65 & 58,5 & 0 & \\
XII & 23 & 45,9 & 25,3 & 30,3 & 44 & 43,8 & 19,2 & 45,4 & 43,7 & 52,6 & 41,6 & 39,3 & 0 \\
\hline
\end{tabular}




\begin{tabular}{lllllllllllll}
\hline Order & 250 & 150 & 120 & 200 & 180 & 230 & 175 & 320 & 220 & 315 & 300 & 215 \\
\hline
\end{tabular}

Sebagai contoh, berdasarkan Tabel 7, dilakukan distributor ke kendaraan atau rute. Penggabungan akan dimulai dari nilai penghematan terbesar karena peneliti berupaya memaksimumkan penghematan. Jadi, dimulai dari nilai jarak sebesar 159,4. Nilai jarak tersebut merupakan penghematan terbesar dari penggabungan antara distributor IV dengan distributor III. Jumlah beban masing-masing adalah 200 dan 120, sehingga ketika digabungkan layak dilakukan karena lebih kecil daripada kapasitas truk angkut. Rute untuk distributor IV dengan distributor III menjadi rute 3 . Total beban untuk rute 3 adalah $200+120=320$.

Berdasarkan hasil perhitungan dalam mengalokasikan distributor kedalam rute atau kendaraan, setelah diketahui hasil perhitungan alokasi ditributor kedalam rute atau kendaraan pengiriman yang dilakukan dengan 5 rute pengiriman distributor, sebagai berikut dalam Tabel 8.

Tabel 8 Rute Pengiriman Distributor Usulan

\begin{tabular}{lll}
\hline Urutan Rute & Beban & Rute \\
\hline IV - III - V & 500 & Rute 3 \\
IX - VII - VIII & 475 & Rute 4 \\
VI - II & 380 & Rute 2 \\
X - I & 460 & Rute 1 \\
XII - XI & 405 & Rute 5 \\
\hline
\end{tabular}

d. Mengurutkan Distributor dalam Rute yang Sudah Terdefinisi

Berdasarkan rute yang telah diperoleh sebelumnya, maka peneliti menentukan urutan distributor yang harus dikunjungi dalam satu rute. Dalam mengurutkannya, digunakan tiga metode yaitu metode nearest insert, metode nearest neighbour, dan metode farthest insert. Berikut adalah hasil yang didapat dengan menggunakan 3 metode tersebut, sebagai berikut pada Tabel 9.

Tabel 9 Perbandingan Hasil Urutan Rute dengan 3 Metode

\begin{tabular}{|c|c|c|c|}
\hline Rute & Metode & Urutan Rute & Total Jarak (km) \\
\hline \multirow[t]{3}{*}{1} & Nearest Insert & $W-I-X-W$ & 111,5 \\
\hline & Nearest Neighbour & W - I - X - W & 111,5 \\
\hline & Farthest Insert & $\mathrm{W}-\mathrm{X}-\mathrm{I}-\mathrm{W}$ & 111,5 \\
\hline \multirow[t]{3}{*}{2} & Nearest Insert & W - VI - II - W & 91,1 \\
\hline & Nearest Neighbour & W - VI - II - W & 91,1 \\
\hline & Farthest Insert & W - II - VI - W & 91,1 \\
\hline \multirow[t]{3}{*}{3} & Nearest Insert & W - IV - V - III - W & 469,7 \\
\hline & Nearest Neighbour & W - IV - III - V - W & 476,5 \\
\hline & Farthest Insert & W - IV - III - V - W & 476,5 \\
\hline \multirow[t]{3}{*}{4} & Nearest Insert & $\begin{array}{l}\text { W - VIII - VII - IX - } \\
\text { W }\end{array}$ & 209,1 \\
\hline & Nearest Neighbour & $\begin{array}{l}\text { W - VIII - VII - IX - } \\
\text { W }\end{array}$ & 209,1 \\
\hline & Farthest Insert & $\begin{array}{l}\text { W - IX - VII - VIII - } \\
\text { W }\end{array}$ & 209,1 \\
\hline \multirow[t]{3}{*}{5} & Nearest Insert & W - XII - XI - W & 92,3 \\
\hline & Nearest Neighbour & W - XII - XI - W & 92,3 \\
\hline & Farthest Insert & W - XI - XII - W & 92,3 \\
\hline
\end{tabular}

Tyas, Optimasi Jalur Distribusi Pada Kopkar PT. YKK AP Indonesia Dengan Metode Saving Matrix 
Untuk rute terpilih dengan total jarak terpendek dapat dilihat pada Tabel 10.

Tabel 10 Urutan Rute Terpilih

\begin{tabular}{llc}
\hline Rute & Urutan Rute & Total Jarak (km) \\
\hline 1 & W - I - X - W & 11,5 \\
2 & W - V I - II - W & 39,3 \\
3 & W - IV - V - III - W & 469,7 \\
4 & W - VIII - VII - IX - W & 209,1 \\
5 & W - XII - XI - W & 92,3 \\
\hline \multicolumn{2}{l}{ Total Jarak } & 921,9 \\
\hline
\end{tabular}

e. Perbandingan Rute Awal dan Rute Baru

Dari data yang diperoleh, langkah selanjutnya adalah menghitung biaya dengan membandingkan pengeluaran yang dilakukan oleh perusahaan. Apabila jarak yang ditempuh dalam pengiriman rute awal diasumsikan kedalam hasil perhitungan biaya operasional perhari sebesar Rp. 480.857/hari.

Tabel 11 Rekapitulasi Jarak Tempuh Rute Distribusi

\begin{tabular}{llc}
\hline Rute & Total Jarak Tempuh $(\mathbf{k m})$ & Total Biaya $(\mathbf{R p})$ \\
\hline Awal & $1.082,8$ & 480.857 /hari atau $14.425 .722 /$ bulan \\
Usulan & 921,9 & $409.706 /$ hari atau $12.291 .180 /$ bulan \\
Selisih & 160,9 & 71.151 /hari atau $2.134 .530 /$ bulan \\
\hline
\end{tabular}

Penggunaan metode saving matrix mampu memperbaiki rute distribusi perusahaan dari 12 rute menjadi 5 rute sehingga bisa mengurangi biaya operasional perusahaan. Penggunaan metode Farthest Insert, Nearest Insert, dan Nearest Neighbour mampu memperpendek jarak yang ditempuh angkutan perusahaan dari 1.082,8 km menjadi 921,8 km. Penggunaan metode saving matrix mampu menghemat pengeluaran perusahaan sebesar Rp. 2.134.530 /bulan.

\section{KESIMPULAN}

Penelitian ini berusaha mengoptimasi jalur distribusi untuk pengiriman produk ke distributor dengan mempertimbangkan jarak dan biaya operasional. Hasil penelitian ini didapatkan bahwa metode saving matrix mampu meminimalkan total jarak tempuh untuk distribusi produk dari 1.082,8 km menjadi $921,9 \mathrm{~km}$. Penggunaan metode saving matrix juga dapat menghemat pengeluaran perusahaan sebesar Rp. 71.151 /hari atau Rp. 2.134.530/bulan dalam menjalankan distribusi produknya. Penelitian ini hanya menggunakan jarak dan biaya operasional dalam mengolah data, alangkah lebih baik lagi penelitian berikutnya mempertimbangkan faktor lainnya, seperti tingkat kepadatan di jalan raya dan waktu pengiriman. Metode yang digunakan untuk penelitian selanjutnya, alangkah lebih baik menggunakan metode optimasi yang lainnya seperti Fuzzy Multi Objective Programming, atau Linear Programming.

\section{REFERENSI}

[1] PT YKK AP Indonesia, “Tentang Kami YKK AP,” YKKAP. https://www.ykkap.co.id/id/tentangkami/ (accessed Dec. 18, 2019).

[2] A. A. L. Mursy, H. Kholiq, D. A. Saptyaningtyas, R. Juliana, M. Sulisdiana, and M. U. Romdhini, "Menentukan Rute Terpendek Pendistribusian Bahan Bangunan oleh PT. Sadar Jaya Manunggal Mataram Menggunakan Algoritma Branch and Bound," Eig. Math. J., vol. 1, no. 1, p. 54, Jun. 2019, doi: 10.29303/emj.v1i1.24.

[3] Muhammad, Bakhtiar, and M. Rahmi, "Penentuan Rute Distribusi Sirup Untuk Meminimalkan Biaya Transportasi," Ind. Eng. J., vol. 6, no. 1, pp. 10-15, 2017.

[4] S. Jaja Raharja, "Analisis Saluran Distribusi Hypermarket Di Kota Bandung," Sosiohumaniora, vol. 15, no. 2, pp. 119-129, Jul. 2013.

[5] F. J. Sesa, H. Syarifudin, and Y. Rizal, "Optimasi Rute Pengiriman Produk dengan Tyas, Optimasi Jalur Distribusi Pada Kopkar PT. YKK AP Indonesia Dengan Metode Saving Matrix 
Meminimumkan Biaya Transportasi Menggunakan Metode Saving Matrix di PT. DEF," UNP J. Math., vol. 2, no. 1, pp. 18-22.

[6] M. Hudori and S. Madusari, "Penentuan Rute Angkutan Tandan Buah Segar (Tbs) Kelapa Sawit Yang Optimal Dengan Metode Saving Matrix," J. Citra Widya Edukasi, vol. 9, no. 1, pp. 25-39.

[7] S. R. Fitri, "Optimasi Jalur Distribusi Produk Dengan Menggunakan Metode Saving Matrix Untuk Penghematan Biaya Operasional," J. Valtech, vol. 1, no. 1, pp. 103-109, 2018.

[8] Supriyadi, K. Mawardi, and A. Nalhadi, "Minimasi Biaya Dalam Penentuan Rute Distribusi Produk Minuman Menggunakan Metode Savings Matrix," ISLI, vol. 6, pp. 1-7, 2017.

[9] N. Ikfan, "Penentuan Rute Transportasi Terpendek Untuk Meminimalkan Biaya Menggunakan Metode Saving Matriks," J. Ilm. Tek. Ind., vol. 12, no. 1, pp. 165-178, 2013.

[10] Nelfiyanti, "Optimasi Rute Pengambilan Barang Titipan Untuk Meminimasi Jarak Tempuh," $J$. Tek. Ind., vol. 1, no. 2, pp. 217-225, Desember 2012.

[11] S. Rahayu, "Perencanaan Jadwal Dan Penentuan Rute Distribusi Produk Otomotif Dengan Metode Saving Matriks," J. Tek. Ind., vol. 20, no. 1, pp. 1-14, 2017.

[12] M. M. Huda, D. Y. Rakhmawati, and H. Nuha, "Penentuan Rute Distribusi Menggunakan Metode Saving Matrix Untuk Meminimalkan Biaya Transportasi Di PT. Lima Jaya Abadi," J. Univ. 17 Agustus 1945 Surabaya, vol. 1, pp. 1-14, 2018.

[13] N. Aprilia, "Penerapan Metode Saving Matrix Untuk Meminimasi Biaya Pengiriman Produk Kemasan Pada PT XYZ,” Sci. J. Ind. Eng., vol. 1, pp. 5-9, 2020.

[14] Suparjo, "Metode Saving Matrix Sebagai Metode Alternatif Untuk Efisiensi Biaya Distribusi (Studi Empirik Pada Perusahaan Angkutan Kayu Gelondongan Di Jawa Tengah)," J. MEDIA Ekon. DAN Manaj., vol. 32, no. 2, p. Juli 2017.

[15] A. Effendi, Y. Ngatilah, and Iriani, "Penentuan Rute Optimal Distribusi Produk Dengan Metode Saving Matrix dan Travelling Salesman Problem Di PT. Romindo Primavetcom," J. Ind. Eng. Manag., vol. 11, pp. 26-34, 2016. 